\title{
Factors controlling reactive iron- wehrlite formation in the upper mantle
}

LEVENTE PATKÓ ${ }^{1,2,3}$, PÉTER LUFFI ${ }^{4,5}$, NORA LIPTAI ${ }^{6}$ AND ISTVÁN JÁNOS KOVÁCS ${ }^{1}$

${ }^{1}$ MTA EK Lendület Pannon Lithoscope Research Group, Centre for Energy Research

${ }^{2}$ Lithosphere Fluid Research Lab (LRG), Eötvös Loránd

University

${ }^{3}$ Geodetic and Geophysical Institute, Research Centre for

Astronomy and Earth Sciences (CSFK)

${ }^{4}$ Institute of Geodynamics, Romanian Academy

${ }^{5}$ Geological Institute of Romania

${ }^{6}$ MTA EK Lendület Pannon LitH2Oscope Research Group, Centre for Energy Research

Presenting Author: levente.patko@ttk.elte.hu

Iron-wehrlites are largely interpreted as reaction products between clinopyroxene-saturated silicate melts and peridotites, as observed in peridotite massifs, ophiolites and upper mantle xenolith series. Although iron-wehrlites tend to occur in all these mantle suites, they represent only a volumetrically subordinate fraction of the coexisting ultramafic lithologies. Hence, so far little attention has been directed at how pressure, temperature, wall rock composition, and melt-rock ratios modulate their formation.

Here we use alphaMELTS [1] to simulate transformations associated with porous and channelized transport of alkali basaltlike liquids (generated via low-degree melting of peridotites at the lithosphere-asthenosphere boundary) through lherzolites, harzburgites, and dunites under various physical conditions of the lithospheric mantle.

Our results suggest that reactions involving a broad spectrum of melt-rock ratios, corresponding to porous and channelized flow regimes, tend to produce dunites, wehrlites, and secondary lherzolites at high, intermediary, and low temperatures, respectively, independently of pressure. The amount of new lithologies formed along the sequence, however, depends on the imposed melt-rock ratio, temperature, pressure, and wall rock composition. Melt-rock reactions simulated along polybaric cooling paths tend to generate a stratification of the metasomatic products, distributing the dunite-wehrlite-secondary lherzolite sequence vertically. These findings may explain why wehrlites are rather rare in the shallow mantle commonly sampled by basalts, and suggests that they should be common in the deeper lithospheric mantle sections affected by melt migration, generally underrepresented in the xenolith record. In high heat flow tectonic settings dominated by significant magma fluxes, such as mid-ocean ridges and arcs, high temperatures along the melt migration paths in the mantle restrict reaction products to dunites; therefore wehrlites tend to be scarce in these settings. In contrast, wehrlitic lithologies are predicted to occur more frequently in the deeper lithospheric mantle of cooler intraplate settings.

[1] Smith \& Asimow (2005), Geochemistry, Geophysics, 